This is an Accepted Manuscript of an article published by Taylor \& Francis in Contemporary Social Science: Journal of the Academy of Social Sciences on $18^{\text {th }}$ April 2018, available online: http://www.tandfonline.com/[https://doi.org/10.1080/21582041.2018.1459818].

\title{
Using Reflexive Lifelines in Biographical Interviews to aid the Collection, Visualization and Analysis of Resilience
}

Jane Gray and Jennifer Dagg

Maynooth University Department of Sociology and Social Sciences Institute

Published as: Jane Gray \& Jennifer Dagg. (2018) Using reflexive lifelines in biographical interviews to aid the collection, visualisation and analysis of resilience, Contemporary Social Science, DOI: $\underline{10.1080 / 21582041.2018 .1459818}$ 


\begin{abstract}
This article demonstrates the use of a reflexive lifeline instrument within a study oriented towards documenting and explaining resilience from a sociological perspective. Informed by both life course and biographical perspectives, our research design comprised two interviews incorporating recursive co-construction of the participant's lifeline. We aimed to meet three objectives with this method: (1) to collect accurate retrospective data about the timing of lives; (2) to garner biographical data that allowed us to explore lives as wholes; and (3) to elicit participant reflexivity on turning points associated with resilience. Our approach was distinctive in its explicit use of the lifeline both as a means to bring life stories into dialogue with life histories, and as a dynamic prompt to engage participants in the reflexive coconstruction of turning points as fateful moments. We illustrate our approach through a case presentation and analysis of the reflexive lifelines co-constructed with two men who participated in our study. We also show how the reflexive lifeline interview generated opportunities for participant-led researcher reflexivity.
\end{abstract}

\title{
Key words
}

Biographical method, reflexivity, resilience, qualitative longitudinal

\section{Funding details}

This project has received funding from the European Union's Seventh Framework Programme for research, technological development and demonstration under Grant Agreement 613245 


\section{Introduction}

Lifelines, sometimes called 'timelines' or 'life maps' (see Neale 2017), are visual depictions of lives, displaying events in chronological order and often indicating their meaning and importance (Nelson, 2010). Scholars have incorporated them as a method of graphic elicitation within biographical interviews across a range of theoretical and methodological perspectives (Adriensen 2012; Gramling and Carr 2004; de Vries 2013). Lifelines and related instruments - such as life history calendars (Freedman et al. 1988) and life grids (Berney and Blane 2013; Nico 2016; Parry et al. 1999; Wilson et al. 2007) - improve the accuracy of participants' recall of the timing, chronology and detail of events (Glasner and van der Waart 2007; Hope et al. 2013). Scholars also use lifelines to encourage participant reflection on the course of their lives (Clausen, 1998; Sheridan et al., 2011), to identify turning points and epiphanies (Hanks and Carr, 2008; Nico and van der Waart, 2012)), and to elicit participant reflexivity within the context of collaborative and participatory research methodologies (Bagnoli, 2009; Jackson, 2012; Kolar et al., 2015; Pfister et al., 2014).

In most published findings, emphasis is placed either on the utility of lifelines for aiding accurate recall of life events, or on their usefulness for enhancing collaboration and reflexivity within the research process. However, Nico (2016, p. 2117) recently argued in favour of a 'mixed technique' to improve 'the quality of the objective information collected (about the timing and order of events, i.e. the life lived) and the subjective information (the life told).' In this article, we extend this approach by demonstrating a lifeline instrument that was explicitly designed to aid recall of key life events and to elicit participant reflection and reflexivity within biographical interviews oriented towards understanding and explaining social resilience. 
The interviews were conducted in 2014 as part of a European project (RESCuE) on household resilience to the 2008 economic crisis (Promberger et al., 2014). Following a shared methodology (see Promberger et al., 2014; Dagg and Gray, 2016), the research occurred across two stages: an initial narrative interview with twenty-four participants and a follow-up photo-elicitation interview with sixteen of the original twenty-four. ${ }^{1}$ Study participants included people living in households displaying varying levels of resilience to economic adversity in an Irish urban centre and its rural hinterland. All follow-up interviews took place within six months of the first phase.

During the follow-up interviews, the Irish team added a reflexive dimension to the lifeline we had constructed in the course of and immediately following the previous narrative interview. This allowed us to interrogate the processes giving rise to resilience by applying concepts from the life course perspective within the 'processual imaginary' (Thomson and McLeod, 2015) of qualitative, biographical research, focusing in particular on 'turning points.' We wanted to learn about the historical and social timing of participants' lives, to elicit their reflections on the meanings of key life transitions and stages, and to engage them in reflexive co-construction of turning points as 'critical moments.'

Later in this article we illustrate our reflexive lifeline method through a comparative discussion of its use with two male participants born in the mid-1950s, showing how it enabled us to understand resilience both in the context of the social timing of their lives and through the identification of turning points when their lives changed direction. We also

\footnotetext{
${ }^{1}$ The shared RESCuE Project design included a visual methodology in the form of a photo elicitation. This involved 16 of the initial 24 participants agreeing to receive a digital camera and to take photos of their daily life experiences guided by a series of prompts. A technical report providing full details of the study design and its implementation in Ireland is available online (Author 1 and Author 2 date). For simplicity, throughout this article we refer to the first interview as the 'narrative interview' and the second interview as the 'reflexive interview.' We do not elaborate on the photo-elicitation phase of the reflexive interview here.
} 
describe how the reflexive lifeline interview created opportunities for 'sticky moments' (Riach 2009) that induced participant-led reflexivity on the part of the research team.

The article begins with a brief introduction to the concept of social resilience and a discussion of how it requires a methodological and analytical approach that can capture process. The second part discusses the usefulness of the concepts of 'turning points' and 'critical moments' for understanding resilience. In part three we describe our implementation of a 'reflexive lifeline' within the study. Part four demonstrates the value of our approach through a discussion and analysis of Larry's and Seamus' biographies. In the conclusion, we discuss some unexpected strengths and challenges of our approach, and suggest some considerations for future work.

\section{Resilience as a social process}

Policy makers and social scientists display growing interest in the concept of resilience, which seeks to identify how people in adverse circumstances adapt, mobilise and transform social resources in order to achieve desired outcomes that sustain and advance their future well-being (Canvin et al., 2009). In opposition to a 'heroic' model focusing on the innate characteristics of individuals and families, critical sociological approaches to resilience emphasize 'the influence of structural conditions and path dependency' (Dagdeviren et al., 2016, p.2).

Following, Estêvão et al. (2017, p. 17), we define resilience as a dynamic process through which those experiencing adversity exercise reflexive agency in the context of rapidly changing social structural conditions following an external shock, such as the recent financial crisis. People take action by mobilizing natural, cultural, social and economic resources, and by shifting risks in time and space. Resilience processes may or may not lead to resilient outcomes, not just because of variation in individual attributes, or due to contingent events, 
but because social structural conditions impinge, in cumulative and developmental ways on the resources that are available to people, and on their capabilities to convert those resources into effective agency (Hobson 2014, p. 12). Thus some of the resources available to people are given in their current social situation, but others are acquired in their family histories and biographies (Promberger 2017, p. 7).

Scholarly and policy concerns about resilience thus resonate with the broader 'temporal turn' within the social sciences and more specifically, with the emergence of a longitudinal 'sensibility' within qualitative research (Thomson and McLeod, 2015). In order to explain it through biographical analysis, we must first identify how people move through time in interaction with personal communities and social institutions, and second, how they accumulate resources and the capabilities to convert them into resilience at times of crisis. We also need to establish how the experience of, and responses to, earlier difficulties and opportunities affect the stock of resources and capabilities that affect agency in the present. Third, because crises commonly have the effect of knocking people's lives off track, creating the risk of continuing 'downward' trajectories, we need ways to grasp the historically and socially situated processes through which lives are 'turned around.' Furthermore, understanding peoples' capabilities requires attention to how they reflect on earlier life experiences as they redefine and transform their practices, identities and life plans. In the next section we describe how the concepts of 'turning point' and 'critical moment,' applied within a qualitative, biographical research strategy, facilitate such an analysis.

\section{Towards a comparative biographical understanding of resilience}

Within the life course perspective (see Alwin, 2012; Elder, 1994; Heinz, 2016), the concept of 'turning point' refers to moments in individual lives when their trajectories change direction, for example, when a downward or negative pathway is turned around (Laub and Sampson, 1993). The related concept of 'critical moment' (Thomson et al. 2002), originated 
in late modern theories of the 'reflexive project of the self' (Giddens, 1991), although it bears similarities to the conceptualization of turning points within the European biographical research tradition (Reimer, 2014, pp. 5-7). Critical moments are events within life narratives that have consequences both for the shape of individual lives and for their identities (Thomson et al., 2002, p. 339); they are moments that combine 'an event and its recognizable effect' (Nico and Van der Waart 2012, p. 144). Such events are 'fateful' when individuals recognize that they are at a crossroads in their lives (Giddens 1991, pp. 142-143) and take action to shape their futures in ways that often entail a re-configuration of their identities (Holland and Thomson, 2009, pp. 454-455).

The identification of turning points thus involves bringing together life histories ('lives as lived') with life stories ('lives as told') (Nico and Van der Waart 2012, p. 146). Identifying those turning points that are 'fateful' is particularly apposite for understanding resilience, which centres on people's agency in reflexively addressing critical moments their lives. People's lives may take turns for better or worse due to chance or circumstance alone, but the concept of resilience implies an active process of re-direction. However, in their discussion of the challenges associated with identifying fateful moments within biographical interviews, Holland and Thomson (2009) cautioned against:

$[\mathrm{M}]$ oving too quickly between evidence of the life as told and interpretations of the life as lived. The critical moment that is found in a single biographical narrative represents a provisional identity claim, which can tell us a great deal about the individual and their circumstances. Yet if one-off life stories are our only form of data, we are limited in what we can see.

Qualitative longitudinal (QL) interviews facilitate the reflexive elaboration of such provisional identity claims through 'recursive interviewing,' that is, by 'revisiting, re- 
visioning and updating a life journey at each successive interview' (Neale 2017, p.18).

This process entails three intertwined 'levels' of reflexivity: 'that of the researcher, that of the individuals being studied and that specifically raised by the research context' (Caetano 2015, p. 231). Within the RESCuE project, we did not have the benefit of an extended QL research design. ${ }^{2}$ However, the reflexive interview allowed the Irish team to develop a fuller understanding of critical moments as fateful by adding a reflexive dimension to the research, allowing us to explore 'how the narrative of a life, the life as told, is continually re-adjusted to the life as lived' (Neale 2017, p. 19). In the next section, we describe how we wove the reflexive lifeline into this simple QL design.

\section{Constructing reflexive lifelines}

Early in the project, two researchers were present during the biographical interviews. This allowed one researcher to conduct the interview while the second focused on the timing of events described by the participant, constructing a draft lifeline. We adopted this approach, in part because we were unsure how feasible it would be for a single interviewer to conduct an in-depth narrative interview while simultaneously drawing up the lifeline. Lifelines, or life grids, are usually constructed as part of the interview (see Nico 2016, p.2116), but we wanted to facilitate a comparatively unstructured biographical narrative consistent with the shared methodology of the RESCuE project. We wished to avoid burdening the participants by extending the interview to include a separate lifeline phase. In a multi-researcher project, we also aimed to establish normative and practical consistency within the team at the outset. ${ }^{3}$ With experience, it became possible for a single interviewer to draft the lifeline while simultaneously conducting the narrative interview. At the conclusion, we clarified details of

\footnotetext{
${ }^{2}$ For introductions to qualitative longitudinal research, see Neale and Flowerdew (2003) and Neale et al. (2012). For an overview of methods of generating data in QL research, including a discussion of life maps, see Neale (2017).

${ }^{3}$ Although somewhat unusual, there are other examples of co-interviewing in qualitative research (see Hanks and Carr 2008, p. 108; Rosenblatt, 2012, p. 103).
} 
the timing of events with each participant, asking, for example, 'in what year did you move abroad'? Subsequently, the researcher cross-referenced the lifeline against the audiorecording of the narrative interview, in order to further clarify key life transitions and events, and to develop initial 'hunches' about what appeared to be 'turning points' within the participant's biography. Figure 1 shows the first, hand-drawn draft of Larry's lifeline. We have disguised some information to protect his confidentiality.

$<$ Figure 1 about here>

Before the follow-up interview, we created a formal representation of the lifeline using a computerised drawing tool. Based on their narrative interviews, we included our initial hunches about turning points in the form of questions with asterisks. We brought two copies printed on A3 sheets to the follow-up interview.

The researcher began by introducing the formal lifeline, briefly describing what we understood to be turning points and inviting the participant to reflect on whether or not they agreed with this interpretation. Participants often suggested additional or alternative examples of turning points within their lives and the interviewer marked up the lifeline accordingly. This introduction was followed by a set of questions oriented towards further co-construction of the reflexive lifeline:

1. I would like you to take a look at the lifeline and tell me if you think it is accurate?

2. Are there any other turning points?

3. On a scale of 0-10 ( 0 being the most unsatisfied/unhappy and 10 being most satisfied/happy) could you put a number beside how that turning point made you feel? 4. Who was most important to you at this time in your life?

5. What number would you attach to your life at present? 
These questions (inspired by the life review interview developed by Clausen (1998)) allowed participants to interact visually with events in their lives. Frequently, they reached for a pen which the researcher had left in easy reach - and inserted events or correct dates, adding words to describe their emotional state at particular turning points. Respondents also wrote numbers corresponding to events other than the agreed turning points. When this occurred the researcher prompted them to 'join the dots,' encouraging them to draw their reflexive lifeline. $<$ Figure 2 about here>

In cases where participants preferred not to do so, the researcher drew their reflexive lifeline according to the scores they had provided, and asked them, once constructed, if this was an accurate portrayal of how they felt their lives had gone. Crucially, this final question allowed the researcher to gain an understanding of how they viewed the current trajectory of their lives. See Figures 3 and 4, which show our (anonymized) graphical representations of Seamus's and Larry's lifelines.

$<$ Figure 3 about here>

$<$ Figure 4 about here>

Throughout this process of co-constructing their lifelines, participants reflected on their lives. As we will describe in more detail below, the co-construction of turning points also elicited participant reflexivity, insofar as it challenged them to think in new ways about critical moments. Frequently, this engagement also gave rise to 'sticky moments' (Riach 2009) in which participants challenged researcher interpretations of turning points, leading us to revise our understanding, not only of the trajectories of these participants' lives, but also of resilience as a social process.

In summary, co-constructing reflexive lifelines in follow-up interviews aided our biographical analysis of resilience in a number of important ways. First, it provided an 
opportunity to check the chronological accuracy of our representation of events and transitions in participant narratives. This enabled us to situate life events with broader sociohistorical contexts (Brannen, 2013). In the course of reflecting on a graphical representation of their life stories, participants often developed more time-structured narratives that linked events to one another in a chronological fashion (Nico 2016). This was an essential aid to subsequent comparison of life trajectories, allowing us to trace the varying effects of shared lives and times. Second, the reflexive lifeline interview allowed us to garner additional information, including more detail about participants' linked lives at significant events, transitions and turning points and a clearer understanding of the progression of their lives. Responses to the question about 'who was important to you' added information about the context of interaction within which choices and deliberations occurred (Caetano, 2015, pp. 228-229).

Third, by encouraging participants to reflect on their lives, inviting them to express how they felt at particular times, the reflexive lifeline interview also elicited participant reflexivity about the direction and course of their lives. As we will show, this was vital for navigating the analytical space between 'turning points,' that may take the form of adaptations to external circumstances structured by practical sense, and 'critical moments' that are founded on reflexivity giving rise to the restructuring of identities. Building on the narrative interview, the reflexive lifeline interview allowed us to maintain an analytical distinction between the 'objective' circumstances, timing and events that structured individual biographies and the 'subjective' processes through which participants took action to re-direct, and give meaning to their lives in the face of adverse events. By inviting participants to coconstruct the 'turning points' on their lifelines, we elicited reflexive engagement and discourse on 'fateful moments.' In this manner, we aimed to specify 'the mediatory process 
that links structural factors with individual agency and reflexivity' (Peterson, 2011, p. 275) within a comparative analysis of biographies that is sensitive to their historical and individual timing. In the next section, we provide a detailed illustration of our approach through an analytical discussion of our interviews with Seamus and Larry.

\section{Reconstructing lives and times}

Seamus and Larry were born in the mid-1950s. When we first interviewed them, both were approaching their sixties, living in rural areas and struggling to make repayments on their mortgages. They each expressed disappointment about the directions their lives had taken. For Seamus, this was 'not what we had planned for.' Larry 'couldn't even tell you what my options are now.'

Their lifelines allowed us to engage in a biographical matching exercise (Crompton, 2001), comparing their life histories in socio-historical context. Figure 5 shows that there were considerable similarities in the timing of key transitions, especially in early adulthood. While average age at marriage reached a historic low in Ireland during the mid-1970s, both men still married exceptionally young. Their early adult transitions were therefore 'ill-timed' in ways that had the potential to impact on their future life paths (Schoon, 2007, p. 97). However, in the context of an expanding economy, they were able to support their young families by working in skilled manual occupations.

$<$ Figure 5 about here $>$

As their families continued to increase, they encountered the recession of the 1980s, with its high rates of unemployment and emigration (Ó Riain, 2014, p. 32). In response to these challenges, Seamus initiated a lifetime pattern of entrepreneurial adaptation through spells of migration to take advantage of opportunities in the construction industry, both within Ireland 
and overseas, and by setting up small businesses in partnership with his wife. Larry, by contrast, responded by entering the civil service because he believed it would provide greater economic security for his family.

They each encountered personal, family problems in the 1990s. In Seamus's case, this led to estrangement from some of his extended family network. In Larry's case, it led to the breakdown of his first marriage. These personal problems contributed to decisions that the men made just as the first phase of the economic boom dubbed the 'Celtic Tiger' began to take off in the mid-1990s (Ó Riain, 2014, pp. 54-59). Seamus and his family returned to Ireland and began construction of their new home in a rural area. Larry moved to a new home in a commuter town.

At the peak of the property bubble that emerged during the second phase of the Celtic Tiger between 2003 and 2008 (Ó Riain 2014, pp. 61-64), both men made critical choices that subsequently increased their families' exposure to the economic crisis. Seamus decided to set up in construction on his own, partly because he had recently been diagnosed with a chronic illness and wanted to avoid the stress of long distance commuting. His adult children had moved out of the family home on which he still had a mortgage. Larry took out a new mortgage to begin building his 'dream' retirement home in a rural area. He did this in the context of a sense that he was 'blocked' from progressing further in his career. Shortly afterwards he met his second wife and started a new family.

As the economic crisis developed, Seamus quickly ran into trouble as clients failed to pay him for his work. Very soon, he and his wife were struggling to pay their mortgage. Seamus became seriously depressed and contemplated suicide 'because I thought logically if I commit 
suicide [my wife will] get the insurance and the house is paid.' He considered reverting to his previous pattern of short-term emigration for work, but felt that he was, 'too old and with depression...I'd have been no good.' Around this time, a relative, visiting from abroad, offered financial help. Soon afterwards, he did secure temporary work overseas, with his son's assistance.

Larry began to feel the impact of salary cutbacks imposed on public sector workers after 2010. The cost of running a car added to the stresses of commuting and coping with the demands of a young family: 'I started getting debts, bills started building up and building up.' In this context, Larry decided he would take advantage of the opportunity to retire comparatively early, available to him in his civil service occupation. Unfortunately, he soon discovered that he had underestimated the value of his pension, which left him with nothing after he had covered his household expenses. He tried to supplement his income by taking on 'cash-in-hand' jobs, but eventually reached a crisis point, when he was forced to seek help from a charity.

At the time of his biographical interview, Seamus had managed to pay off some of his mortgage and had re-negotiated payments on the remainder. While this allowed him to keep his head above water, it meant that he would not own the property until he was seventy, which was 'not the plan, it was to own it this year or last year.' He was working in manual labour on a state-sponsored employment scheme. Seamus felt that, in his new work, he had gone 'from way up there to way down there.' Larry, on the other hand, told us that he still did not know 'what to do.' He was pleased that his family had got through Christmas without charitable help and was contemplating taking on a seasonal manual job offered through an 
acquaintance. He was concerned, however, that it might not be 'worth it' after tax and the costs of running a second car.

By drawing up their lifelines alongside their narrative biographical interviews, we were able to reconstruct and compare the timing and sequencing of Seamus's and Larry's lives in a manner that permitted 'association of the 'history of events'... with the history of decisions, reflections and regrets' (Nico, 2016, p. 2118). In the context of their 'historical times' (Elder, 1994), both men engaged in resilience practices that, cumulatively, affected the stock of resources and capabilities available to them as they faced the economic crisis in their fifties. In a growing economy, both were able to overcome childhood difficulties and the challenge of early adult transitions. By taking strategic decisions, they responded resiliently to the 1980s recession, but the costs exacted by this response left them less well able to cope with subsequent challenges in their personal lives, precipitating them towards choices that made their families more vulnerable to the financial crash. At the end of their biographical interviews, both appeared uncertain about whether or not they would be able to adapt resiliently. In the next section, we show how the follow-up, reflexive interview revealed new insights into the dynamic relationship between Larry's and Seamus's 'lives as lived' and 'lives as told,' by revisiting their narratives and by eliciting reflexivity on turning points.

\section{Eliciting participant reflexivity}

Figures 2 shows that, in the co-construction exercise during his reflexive interview, Seamus depicted a lifeline that was now on an upward trajectory, following a steep downward trend that began when he set up his own business. By contrast, Larry (Figure 3) depicted a continuing negative trend beginning shortly after he started construction on his new home. In the course of adding scores to their turning points, both men suddenly disclosed new developments that had occurred since their narrative interviews. Seamus told us that: 
I've always been a 'half-full' guy, I've always been that way. And it was only in this period here, the depression period, that I got down below into the minus. But I'm back up again to the 'half-full' because I'm heading [overseas], [...], to take a foreman's job. Larry revealed:

I've a sad story for you now...I'm selling the house, I have to sell it, banks are at me. So that's where I'm at. And I'd say the last while here, the last couple of weeks, probably since you're gone, I'm very down. I'm stressed out, I'm all over the place, and I'm up one minute, down the next minute: all over the place. And so it's taken me a while to accept that I have to sell it.

At first, therefore, Seamus linked his 'resilient' lifeline to a critical event that provided him with an opportunity for agency, which would restore a former identity. Larry, on the other hand, associated his apparently 'non-resilient' trajectory with a critical event that he had yet to convert to a 'fateful' one, because he had not accepted the change of direction it would bring to his life and self-identity. However, in the course of their reflexive interviews, both men challenged their own initial interpretations.

Seamus projected two selves to the interviewer, both his former identity as a strong 'leader' in his family and his current sense of reliance on a web of related others, notably including his adult children. He revealed that his wife did not want him to avail of the new employment opportunity. At the end of his reflexive interview, he acknowledged that he probably would not take it up. Larry described how he and his wife planned to move into a new home with her parents. He returned continually to questions about the feasibility of the new arrangement and his sadness at the loss of his dream retirement home, revealing that he had yet to convert this critical moment into a fateful one. Nevertheless, he described having achieved a greater sense of self-awareness in the course of the interview: 
I can say I don't know what's around the bend now, where before my life was there like that, and then "Oh" it's stopped, do you understand? And that's what I would say to you, my life went "Uh, boom!", and you kind of said where's it going?... [B]ut now I'm kind of expressing myself a bit better aren't I in a sense...[Y]ou can see...coming in... awareness is there.

Thus the process of engaging with us through consideration of the graphical representation of their lifelines - with 'a voice that sits 'on top' of the original interview data' (Riach 2009, p. $364)$ - elicited participant reflexivity on the direction of their lives. In both cases, this took the form of provisional identity claims that involved surrendering past dreams and coming to terms with their reliance on others. For Larry this meant a process of 'shifting risk' by moving in with his in-laws, whereas for Seamus it took the form of drawing on the social and economic resources available to him, once he had accepted that he was no longer a 'leader' in his family. Both of these turning points towards resilience exacted costs, but Seamus showed greater signs of converting this critical moment into a fateful one, coming to terms with his new identity, whereas Larry described himself as being unable to 'see what is around the bend.'

\section{Participant induced reflexivity}

In the section above, we showed how engaging in the co-construction of reflexive lifelines elicited participant reflection on their biographies. In this section, we present two examples of how the discussion of turning points in the reflexive lifeline interviews also created opportunities for what Riach (2009) described as 'sticky moments,' during which participants exercised 'symbolic mastery' in ways that facilitated an open exchange of the different positions taken by researcher and researched.

During his first, narrative interview, Seamus gave a striking account of how an elderly relative, visiting from overseas, gifted his family money to pay off some of their debt. We 
thought that this intervention might be a significant 'turning point,' because it occurred when his financial circumstances were at their lowest, and seemed to mark a point at which they began to turn around. Seamus noted that, after her intervention, he was beginning to 'get stronger.' However, during his reflexive interview, in the course of 'joining the dots,' Seamus challenged our interpretation:

For me it was going out to [overseas city], I suppose, my son in [overseas city], and getting work again, and actually being wanted. And getting paid well for doing what I was doing. That was a big...[whistles]...that made me feel really good.

This occurred shortly after his relative's intervention. This 'sticky moment' caused us to reflect on our assumption that material adversity represented the most significant challenge to resilience and that the importance of social capital lay solely in its potential for conversion into economic capital (Bourdieu 1990). Re-reading the transcripts of his interviews in light of this reflexive moment, led us to a greater appreciation of the symbolic importance of how Seamus positioned himself within the 'linked lives' in his biography, and how this was critical to his capacity for resilience. This aligns with Lamont et al.’s (2013, p. 135) argument that resilience is maintained by 'repertoires that sustain recognition... of individual or collective selves.'

In Larry's case, we initially viewed his decision to retire as a critical moment that precipitated his personal financial crisis. However, Larry rejected this understanding of his retirement as a turning point, emphasizing instead that it represented something positive in his life, associated with the construction of his dream home. While not denying that he had miscalculated, Larry depicted the timing of his retirement, not as a turning point, but as part of a slow downward trend, linked to growing financial difficulties after 2008: 
I'd planned on [retiring] - I had all the paperwork done, I'd every kind of ...in my head, I'd everything sorted. I'd asked, "Look where are we going?" And then from 2008 say to $2010[\ldots]$ we lost half our pay and we're doing three times the work now, you probably are the same. And it just... So why I retired was I couldn't get to work sometimes, I didn't have the fuel to get to work.

Larry's interpretation of his retirement experience led us to a greater appreciation of how his decision had been made in the context of a 'moral rationality' based on quality of life and his desire to spend more time with his young family, rather than an 'economically rational' choice (Duncan and Edwards 1999). Furthermore, Larry's appeal to us as fellow public servants, led us to reflect on own positionality in relation to the research topic (Riach 2009, p. 364), and how this might have affected our initial interpretations. Such moments of 'participant-induced' reflexivity contributed towards making our research 'accountable '(Henwood 2008).

\section{Conclusion}

We have defined resilient biographies as situated, developmental processes through which people acquire capabilities to mobilize resources in ways that maintain their well-being, or quality of life, under challenging and adverse conditions. Resilience to shocks such as the recent 'great' recession may require people to turn their lives around in ways that entail a reconfiguration of their identities. Social resilience is therefore a fundamentally reflexive process, situated within past and present structural and institutional contexts.

In this article, we described how we investigated resilience using a 'reflexive lifeline' method of graphic elicitation within recursive biographical interviews. We illustrated our approach through a comparative analysis of the interviews and lifelines co-constructed with two men who participated in our study. The reflexive lifelines met a number of objectives for a comparative biographical analysis of resilience. Using them, we collected 'objective' 
retrospective data about the timing of lives to facilitate comparison, garnered biographical data that allowed us to explore subjective meanings, and elicited reflexive data on turning points as fateful moments. The lifeline method enabled us, as researchers, to retain an analytical distinction between the 'life as lived' and the 'life as told,' while collaboratively reconstructing participants' life experiences and understandings (Nico 2016). The reflexive lifeline interview allowed us to explore resilience as a process through which participants 'overwrote' their pasts and re-imagined their futures (Neale, 2017, p. 18). It also provided unexpected opportunities for researcher reflexivity, challenging some of our 'taken-forgranted' ideas about resilience. We believe that the reflexive lifeline method holds potential for biographical research on a wide range of topics. As a method that creates a 'feedback loop between participant narratives and research data,' it does require a high degree of ethical sensitivity (Neale 2017, p. 20).

One of the challenges for biographical research in social science is that it may appear to 'individualize' topics such as resilience, placing undue emphasis on contingent events, agency, and the unique characteristics of individuals, ignoring the determining effects of wider socio-historical contexts and structural constraints. However, we believe that the reflexive lifeline approach outlined here, helps to capture what Abbott (2017, p. 13) described as the 'historicality of individuals,' that is, the 'encoded historical experience' that at any given moment 'constitutes a set of possibilities and constraints within which various actors must work in the present.' It also allows us to uncover and explore the 'reflexive competences' (Caetano, 2015) through which people act to address critical life events. Both layers of interpretation and analysis are essential to a biographical understanding of resilience. 


\section{References}

Abbott, A. (2017). Processual Sociology. Chicago: University of Chicago Press.

Adriansen, H. K. (2012). Timeline interviews: A tool for conducting life history research. Qualitative studies, 3(1), 40-55.

Alwin, D. F. (2012). Integrating varieties of life course concepts. The Journals of Gerontology Series B: Psychological Sciences and Social Sciences, 67B(2), 206-220

Bagnoli, A. (2009). Beyond the standard interview: the use of graphic elicitation and arts based methods. Qualitative Research 9(5), 545-570.

Berney, L. and Blane, D. (2003). The Lifegrid Method of Collecting Information From People at Older Ages. Research in Policy and Planning, 21(2), 13-22.

Brannen, J. (2013). Life story talk. Some reflections on narrative in qualitative interiews. Sociological Research Online, 18(2), URL: http://www.socresonline.org.uk/18/2/15.html>

Caetano, A. (2015). Personal reflexivity and biography: methodological challenges and strategies. International Journal of Social Research Methodology, 18(2), 227-242,

Canvin, K., Marttila, A., Burstrom, B., \& Whitehead, M. (2009). Tales of the unexpected? Hidden resilience in poor households in Britain. Social Science \& Medicine, 69(2), 238-245.

Clausen, J. (1989). Life reviews and life stories. In J.Z. Giele and G. H. Elder, Jr. (eds). Methods of Life Course Research: Qualitative and Quantitative Approaches (pp. 189212). Thousand Oaks, California: Sage.

Crompton, R. (2001). Gender, Comparative Research and Biographical Matching. European Societies 3(2), 167-190. 
Dagdeviren, H., Donoghue, M. and Promberger, M. (2016). Resilience, Hardship and Social Conditions. Journal of Social Policy, 45(1), 1-20.

Dagg, J. and Gray, J. (2016) RESCuE technical report on fieldwork in Ireland. NIRSA Working Paper 83. Available at:

https://www.maynoothuniversity.ie/sites/default/files/assets/document/JDand\%20JGNo83_0. pdf

De Vries, B. (2013). Lifelines: A review of content and context. International Journal of Reminiscence and Life Review, 1(1), 31-35.

Elder Jr, G. H. (1994). Time, human agency, and social change: Perspectives on the life course. Social Psychology Quarterly, 57(1), 4-15.

Estêvão, P., Calado, A., \& Capucha, L. (2017) Resilience: Moving from a "heroic" notion to a sociological concept. Sociologia, Problemas e Práticas 85, 9-25.

Freedman, D., Thornton, A., Camburn, D., Alwin, D., \& Young-DeMarco, L. (1988). The Life History Calendar: A Technique for Collecting Retrospective Data. Sociological Methodology, 18, 37-68.

Giddens, A. (1991). Modernity and self-identity: Self and society in the late modern age. Stanford, CA: Stanford University Press.

Gramling, L.F. and Carr, R.L. (2004). Lifelines: A Life History Methodology. Nursing Research 53(3), 207-210.

Hanks, R. and Carr, N.T. (2008). Lifelines of Women in Jail as Self-Constructed Visual Probes for Life History Research. Marriage and Family Review 42(4), 105-116.

Heinz, W. (2016). “Conceptual foundations of qualitative life course research”, Sociologia, Revista da Faculdade de Letras da Universidade do Porto, Número Temático Famílias e Curso de Vida. Potencialidades, limites e desafios metodológicos, pp. 20 37 
Henwood, K. (2008). Qualitative Research, Reflexivity and Living with Risk: Valuing and Practicing Epistemic Reflexivity and Centering Marginality. Qualitative Research in Psychology, 5(1), 45-55

Hobson, B. (2014). Worklife balance: the agency and capabilities gap. Oxford: Oxford University Press.

Holland, J. and Thomson, R. (2009). Gaining perspective on choice and fate: revisiting critical moments. European societies, 11(3), 451-469.

Hope, L, Mullis, R \& Gabbert, F. (2013). Who? What? When? Using a timeline technique to facilitate recall of a complex event. Journal of Applied Research in Memory and Cognition, 2(1), 20-24.

Jackson, K.F. (2012). Participatory diagramming in social work research: Utilizing visual timelines to interpret the complexities of the lived multi-racial experience.' Qualitative Social Work, 12(4), 414-432.

Kolar, K., Ahmad, F., Chan, L. \& Erickson, P.G. (2015). Timeline Mapping in Qualitative Interviews: A Study of Resilience With Marginalized Groups. International Journal of Qualitative Methods 14(3), 13-32.

Laub, J. H., \& Sampson, R. J. (1993). Turning Points in the Life Course: Why Change Matters to the Study of Crime. Criminology, 31(3), 301.

Neale, B. (2017). Generating Data in Qualitative Longitudinal Research: A methodological review. Timescapes Working Paper no. 8. Available at:

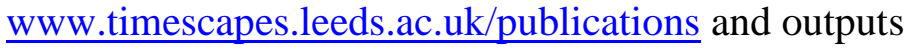

Nelson, I.A. (2010). From Quantitative to Qualitative: Adapting the Life History Calendar Method. Field Methods, 22(4), 413-428. 
Nico, M. L. (2016). Bringing life "back into life course research": using the life grid as a research instrument for qualitative data collection and analysis. Quality and Quantity (50)5, 2107-2120.

Nico, M.L and Van der Vaart, W. (2012). Between an "undoable science" and a "new kind of research": life course methods to study turning points and landmarks. In: Kunneman, H. (ed.) Good work: the ethics of craftsmanship. Amsterdam: Humanistics University Press, 170-182.

Ó Riain, Seán. 2014. The Rise and Fall of Ireland's Celtic Tiger: Liberalism, Boom and Bust. Cambridge: Cambridge University Press.

Parry, O., Thomson, C. and Fowkes, G. (1999) 'Life Course Data Collection: Qualitative Interviewing Using the Life Grid', Sociological Research Online 4(2), URL: http://www socresonline.org.uk/4/2/parry.html

Peterson, A. (2011). The 'Long Winding Road to Adulthood: A Risk-filled Journey for Young People in Stockholm's Marginalized Periphery. Young, 19(3), 271-289

Pfister, A.E., Vindrola-Padros, C., \& Johnson, G.A. (2014). Together we can show you: Using Participant-Generated Visual Data in Collaborative Research. Collaborative Anthropologies 7(1), 26-49.

Promberger, M., Huws, U., Dagdeviren, H., Meier, L. Sowa, F., Boost, M., Athanasiou, A., Arnal, M., Capucha, L., de Castro, C., Faliszek, K., Gray, J., Lecki, K., Mandrysz, W., Petraki, G., Revilla, J.C., Sengul, T., Slania, B., Tennberg, M., Vuojala-Magga, T., \& Wodz, K. (2014). Patterns of Resilience during Socioeconomic Crises among Households in Europe (RESCuE). Concept, Objectives and Work Packages of an EU FP 7 Project. IAB Discussion Paper 5/2014. Available at: http://doku.iab.de/forschungsbericht/2014/fb0514.pdf

Promberger, M. (2017). Resilience among vulnerable households in Europe: Questions, 
concept, findings and implications. IAB Discussion Paper 12/2017. Available at: http://www.iab.de/966/section.aspx/Publikation/k170412301

Reimer, D. (2014). Subjective and Objective Dimensions of Turning Points. Social Work \& Society, 12(1), 1-19.

Riach, K. (2009). Exploring Participant-centred Reflexivity in the Research Interview. Sociology, 43(2), 356-370

Riessman, C. (2002) 'The analysis of personal narratives', in Gubrium, J. (Ed.), Handbook of narrative research. Thousand Oaks, CA: Sage. pp. 695-710.

Schoon, I. (2007). Adaptations to changing times: Agency in context. International Journal of Psychology, 42(2), 94-101

Sheridan, J., Chamberlain, K. \& Dupuis, A. (2011). Timelining: Visualizing Experience. Qualitative Research, 11(5), 552-569.

Thomson, R., Bell, R., Holland, J., Henderson, S., McGrellis, S. and Sharpe, S., (2002). Critical moments: Choice, chance and opportunity in young people's narratives of transition. Sociology, 36(2), 335-354.

Thomson, R. and McLeod, J. (2015). New frontiers in qualitative longitudinal research: an agenda for research. International Journal of Social Research Methodology, 18(3), 243-250.

Wilson, S, Cunningham-Burley, S., Bancroft, A., Backett-Milburn, K. and Masters, M. (2007). Young people, biographical narratives and the life grid: young people's accounts of parental substance use. Qualitative Research, 7(1), 131-151. 
INK.HR. 002.

Figure 1. Hand-drawn lifeline (anonymised) completed during narrative interview with Larry.

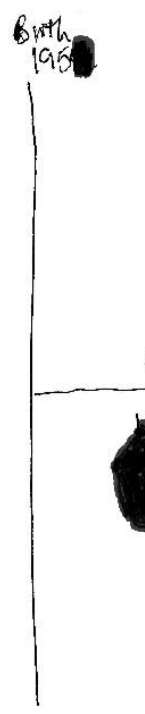

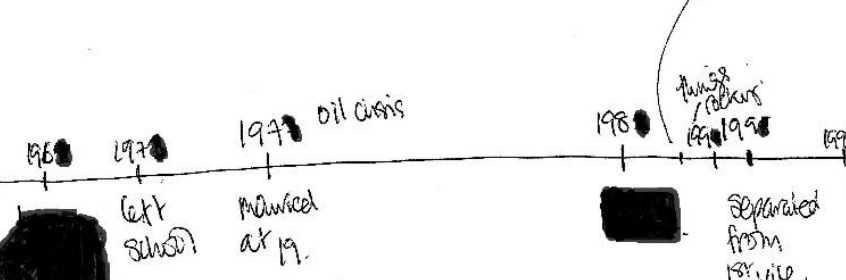

apeneinticesnip

frife

$$
\begin{aligned}
& 7 \mathrm{am}-10 \mathrm{pm} \\
& 7 \mathrm{am}-11 \mathrm{pm}
\end{aligned}
$$

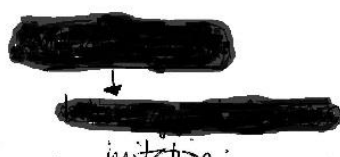

incitation becance pant of the sustem

2 qeans. Fulled ont.

equalitur introduced 10 years solid.

Coprigither

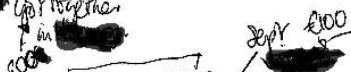

thinking

refrement. 1 is position

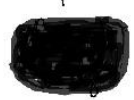

porkgige. pronustion.

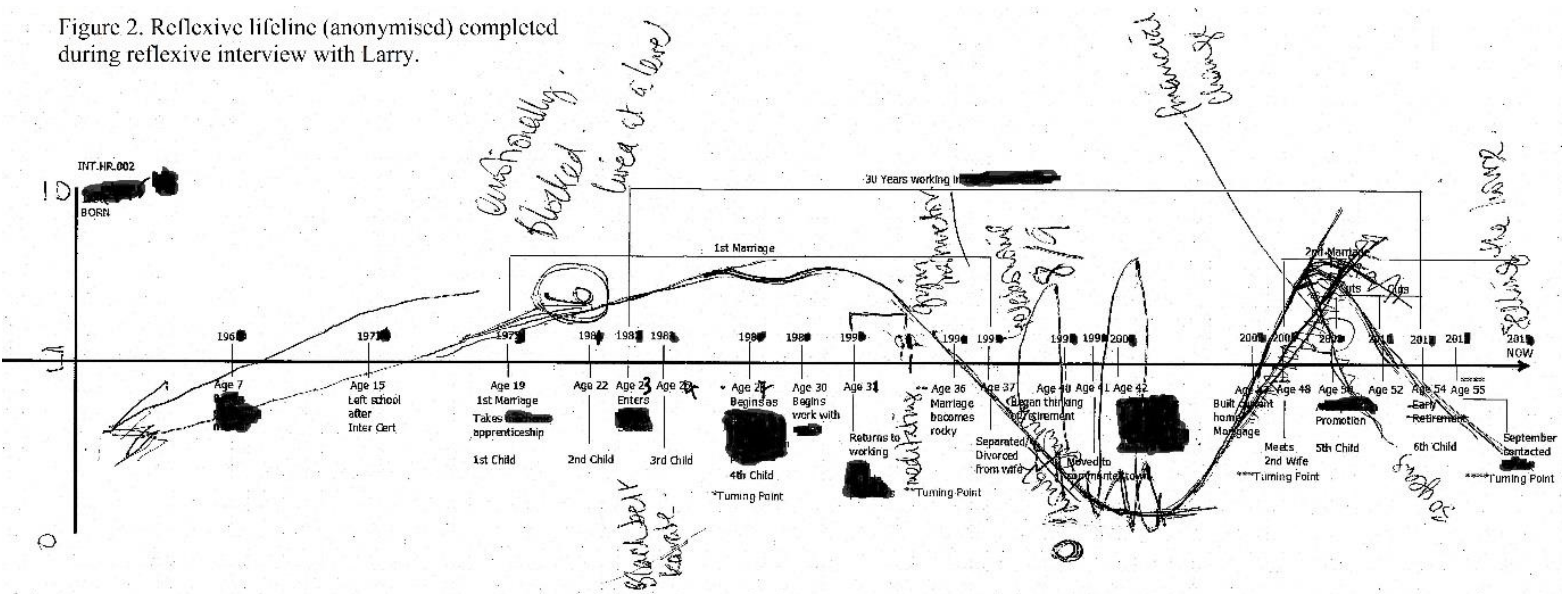

Figure 3. Seamus's anonymised lifeline

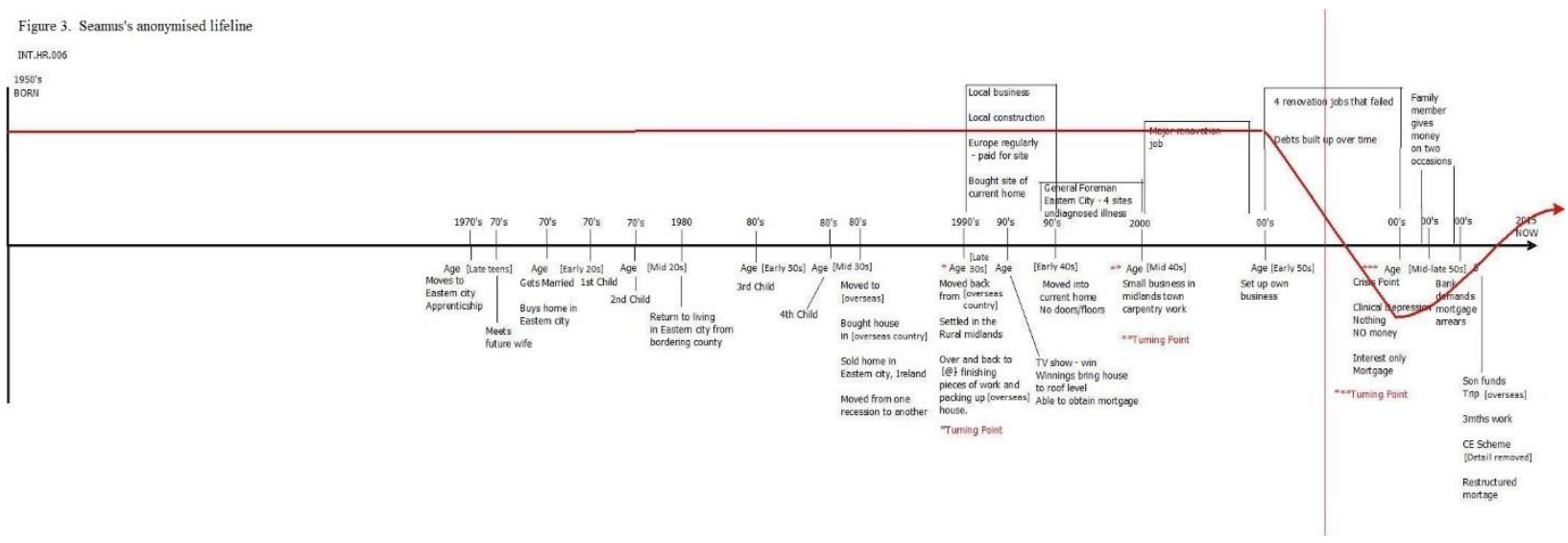


Figure 4. Larry's anonymised lifeline

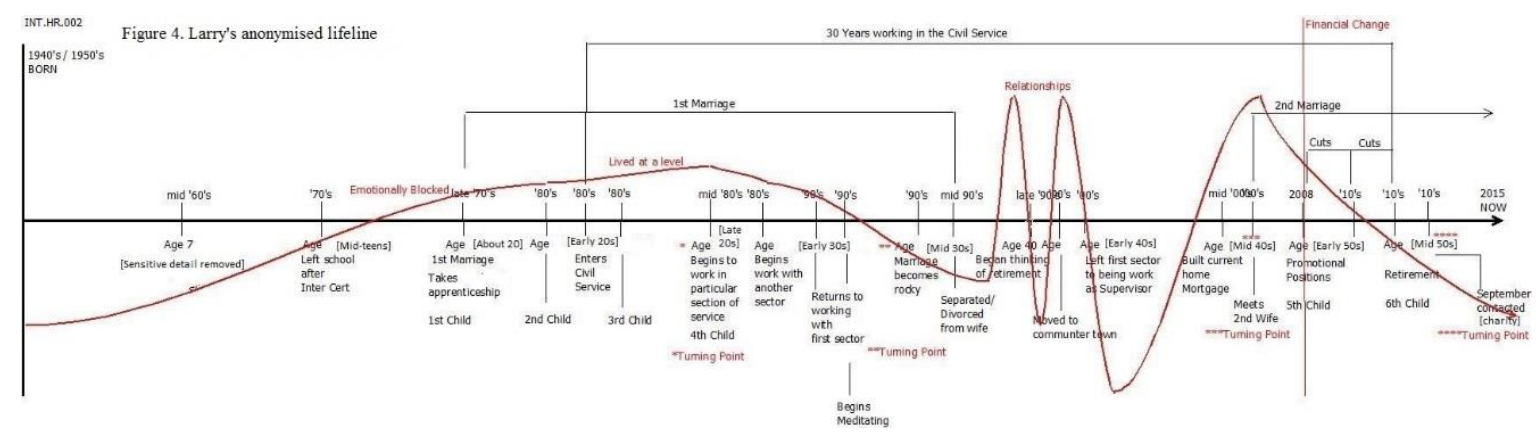

Figure 5. Larry's and Seamus's lives and ties

\begin{tabular}{|c|c|c|c|c|c|c|c|c|c|}
\hline Decade & $1950 \mathrm{~s}$ & $1960 \mathrm{~s}$ & $1970 \mathrm{~s}$ & $1980 \mathrm{~s}$ & $1990 \mathrm{~s}$ & $2000 \mathrm{~s}$ & 2008 Crisis & 20105 & 2015 RESCUE \\
\hline Larry & Childhood & $\begin{array}{l}\text { Adolescence. } \\
\text { Awareness of } \\
\text { family } \\
\text { problems. }\end{array}$ & $\begin{array}{l}\text { Leaves school. } \\
\text { Apprenticeship. } \\
\text { Marriage. First } \\
\text { Child. }\end{array}$ & $\begin{array}{l}\text { Moves to } \\
\text { civil service } \\
\text { occupation. } \\
\text { Three } \\
\text { children } \\
\text { born. }\end{array}$ & $\begin{array}{l}\text { Dealing with } \\
\text { childhood } \\
\text { memories. } \\
\text { Separation. } \\
\text { Moves to } \\
\text { commuter } \\
\text { town. }\end{array}$ & \begin{tabular}{|l} 
Builds house \\
in rural area. \\
Meets \\
second wife.
\end{tabular} & $\begin{array}{l}\text { Birth fifth } \\
\text { child. }\end{array}$ & \begin{tabular}{|l|} 
Austerity \\
cuts. Retires. \\
Sixth child \\
born. Critical \\
financial \\
difficulties.
\end{tabular} & $\begin{array}{l}\text { Struggling to } \\
\text { accept decision } \\
\text { to sell house } \\
\text { and move in } \\
\text { with wife's } \\
\text { family. }\end{array}$ \\
\hline Seamus & Childhood & $\begin{array}{l}\text { Adolescence. } \\
\text { Growing up } \\
\text { in difficult } \\
\text { social } \\
\text { environment. }\end{array}$ & $\begin{array}{l}\text { Moves to } \\
\text { Eastern city. } \\
\text { Apprenticeship. } \\
\text { Marriage. Two } \\
\text { children born. }\end{array}$ & $\begin{array}{l}\text { Third and } \\
\text { fourth } \\
\text { children } \\
\text { born. Moves } \\
\text { with family } \\
\text { to UK for } \\
\text { work. }\end{array}$ & $\begin{array}{l}\text { Dealing with } \\
\text { family } \\
\text { problem. } \\
\text { Returns to } \\
\text { Ireland to } \\
\text { work. Builds } \\
\text { new home in } \\
\text { rural area. } \\
\text { Undiagnosed } \\
\text { illness. }\end{array}$ & $\begin{array}{l}\text { Illness } \\
\text { diagnosed } \\
\text { and treated. } \\
\text { Sets up own } \\
\text { business. } \\
\text { Accumulates } \\
\text { debt. }\end{array}$ & $\begin{array}{l}\text { Customers } \\
\text { refuse } \\
\text { payment. }\end{array}$ & $\begin{array}{l}\text { Critical } \\
\text { financial } \\
\text { difficulties. } \\
\text { Family } \\
\text { interventions. } \\
\text { Restructures } \\
\text { mortgage. }\end{array}$ & $\begin{array}{l}\text { Struggling to } \\
\text { accept new } \\
\text { circumstances. }\end{array}$ \\
\hline
\end{tabular}

